\title{
ANALISIS GREEN IMAGE, PERCEIVED CSR CAPABILITY dan CUSTOMER PERCEPTION OF CSR ACTIVITIES: ETHICAL CSR TERHADAP CUSTOMER LOYALTY
}

\author{
Riska Ermawati ${ }^{(1)}$, \\ Fakultas Ekonomi, Universitas Sarjanawiyata Tamansiswa Yogyakarta ${ }^{(1)}$ \\ Email : ${ }^{1}$ rizkaerma66@gmail.com \\ Ida Bagus Nyoman Udayana ${ }^{(2)}$, \\ Fakultas Ekonomi, Universitas Sarjanawiyata Tamansiswa Yogyakarta ${ }^{(2)}$ \\ Email : ${ }^{2}$ udayana@ustjogja.ac.id \\ LTH Hutami ${ }^{(3)}$ \\ Fakultas Ekonomi, Universitas Sarjanawiyata Tamansiswa Yogyakarta ${ }^{(3)}$ \\ Email : ${ }^{3}$ trialusia@ustjogja.ac.id
}

\begin{abstract}
ABSTRAK
This study aims to see the effect of Green Image on Customer Perceptions of CSR Activities: Ethical CSR, The Effect of CSR Capability on Customer Perceptions of CSR Activities: Ethical CSR and the influence of Customer Perceptions on CSR Activities: Ethical CSR on Customer Loyalty. The population in this study were students and students of Sarjanawiyata Tamansiswa University who had used or are still using products from The Body Shop, with a sample of 105 respondents. The sampling technique in this study used a non-probability sampling technique with purposive sampling.

The results showed that there was a positive effect of green image on customer perception of CSR activities: ethical CSR, there was a positive influence on perceived CSR capability on customer perception of CSR activities: ethical CSR and there was a positive effect on Customer Perception Of CSR Activities: Ethical CSR on Customer Loyalty.

Kata Kunci : Green Image, Customer Perception Of CSR Activities: Ethical CSR, Perceived CSR Capability, Customer Loyalty
\end{abstract}

\section{PENDAHULUAN}

Kerusakan lingkungan hidup dari waku ke waktu semakin parah sehingga memancing keprihatinan yang berakibat pada pemanasan global, penipisan lapisan stratosfir ozon, pencemaran laut, sungai, kebisingan, polusi, hujan asam dan desertifikasi. Kerusakan merujuk ke arah degradasi lingkungan, walaupun tidak mencapai tingkatan yang berbahaya, tapi sudah mencapai pada tingkat menurunnya kualitas bumi sebagai tempat tinggal (Ardianti, 2008). Kondisi lingkungan yang sudah rusak menimbulkan kesadaran masyarakat untuk menjaga kelestarian lingkungan dengan cara menerapkan prinsip 4R yaitu mengurangi pemakaian barang yang tidak berguna (Reduce), mamakai ulang barang yang masih bisa digunakan (Reuse), mendaur ulang barang atau sampah untuk menjadi barang yang berguna (Recycle), dan menimbun sampah organik untuk dijadikan kompos (Replant). Didorong oleh kesadaran akan pelestarian lingkungan, masyarakat menuntut produsen tidak hanya memperhatikan atribut pemasaran, seperti harga, kualitas promosi dan ketersediaan tetapi juga menuntut produsen peduli terhadap lingkungan (Harris, 2006).Konsumen yang menuntun produsen agar berperilaku seperti itu disebut dengan istilah konsumen hijau.

Herri (2006) mendefiniskan produk hijau adalah produk yang tidak berbahaya bagi manusia dan lingkungannya, tidak boros sumber daya, tidak menghasilkan sampah berlebihan. Produk hijau biasanya tahan lama, tidak beracun, terbuat dari bahan yang bisa 
didaur ulang. Desakan konsumen akan produk yang ramah lingkungan membuat produsen mulai mengubah orientasi usaha. Salah satu cara produsen untuk memenuhi kebutuhan dan keinginan konsumen hijau sekaligus untuk menunjukkan tanggung jawab sosialnya terhadap lingkungan adalah dengan menawarkan produk hijau.

Green image memiliki keterkaitan dengan aspek ekologis dimana pengertian dari green image sendiri adalah persepsi konsumen yang menganggap bahwa produk yang terjual dipasaran ramah lingkungan dan tidak berdampak buruk bagi kesehatan. Hubungan green image dengan konsumen hijau adalah konsumen yang memiliki kepedulian terhadap lingkungan dan memiliki kecenderungan untuk memilih dan membeli produk ramah lingkungan dalam memenuhi kebutuhan dan keinginannya serta sekaligus akan mendukung bisnis yang berkaitan dengan lingkungan (Kaufmann, 2012).

Selain itu perceived CSR capability adalah perusahaan yang memiliki tanggung jawab dalam kebijakan untuk berperilaku etis dan memberikan dampak positif terhadap masyarakat dan perkembangan ekonomi yang berkelanjutan. Keterkaitan antara perceived CSR capability dengan konsumen hijau bagaikan pelindung dan penolong bagi perusahaan untuk meminimalkan dampak buruk yang disebabkan suatu krisis. Demikian pula saat perusahaan diterpa kabar buruk dan ketika perusahaan melakukan kesalahan, masyarakat cenderung lebih mudah memahami dan memaafakannya. Dewi (2011) menyatakan bahwa $C S R$ merupakan pemanfaatan sumber daya yang ada demi mencapai keuntungan yang sesuai dengan aturan tanpa kecurangan.

Selanjutnya customer perception of CSR activities: ethical CSR adalah perilaku etis perusahaan yang dapat dibuktikan apabila perusahaan melakukan tindakan yang benar dan sesuai aturan, sedangkan perilaku tidak etis bisa dibuktikan jika perusahaan melakukan aktifitas menyimpang. Hubungan customer perception of CSR activities: ethical CSR dengan konsumen hijau adalah secara etis perusahaan juga bertanggungjawab untuk mempraktekkan hal-hal yang baik dan benar sesuai dengan nilai-nilai, etika, dan norma -norma kemasyarakatan. Melaksanakan CSR secara konsisten dalam jangka panjang dapat menumbuhkan citra yang positif dari masyarakat terhadap kehadiran perusahaan. Kondisi seperti itulah yang pada gilirannya dapat memberikan keuntungan ekonomi bisnis kepada perusahaan yang bersangkutan. Dengan pemahaman seperti itu, dapat dikatakan bahwa, etis CSR adalah prasyarat perusahaan untuk bisa meraih legitimasi sosiologis kultural yang kuat dari masyarakatnya (Achda, 2006).

Customer loyalty adalah perilaku dimana pelanggan bertahan dan berlangganan serta melakukan pembelian ulang pada produk yang sama dan konsisten pada pilihannya sampai masa yang akan datang. Ikatan antara customer loyalty dengan konsumen hijau merupakan loyalitas konsumen pada umunya adalah suatu sikap yang merujuk pada tingkat keterkaitan konsumen terhadap pemilihan dan pemakaian suatu produk. Semakin besar niat pelanggan untuk membeli ulang atau merekomendasikan suatu perusahaan jasa, hal tersebut mengindikasikan bahwa perusahaan jasa tersebut mempunyai bisnis yang cemerlang di masa depan. Sehingga dimensi sikap ini dapat dijadikan indikasi yang baik untuk pengukuran loyalitas pelanggan.

Data dari AC Nielsen menggambarkan bahwa adanya perhatian yang besar dari konsumen Indonesia terhadap beberapa isu lingkungan. Konsumen Indonesia yang memiliki perhatian terhadap isu lingkungan berada di atas 90 persen. Salah satu produk kosmetik yang mampu memanfaatkan peluang pasar di Indonesia adalah The Body Shop, perusahaan tersebut mengklaim bahwa produknya merupakan produk yang ramah lingkungan. Satu diantara banyak perusahaan kosmetik yang punya komitmen untuk melestarikan lingkungan. The Body Shop meluncurkan kampanye terbarunya yaitu "Green Month Campaign: Say No to Plastic". Kampanye ini bertujuan untuk memberi 
pengetahuan bagi masyarakat agar lebih peduli terhadap isu lingkungan dan melindungi bumi dari kerusakan. Kegiatan kampanye yang dilakukan adalah bukti partisipasi The Body Shop dalam momen Earth Hour (23 Maret) dan Hari Bumi (22 April) yang lalu.

Berdasarkan uraian di atas, maka penulis bertujuan untuk meneliti pengaruh Green Image, Perceived Csr Capability Dan Customer Perception Of Csr Activities: Ethical Csr Terhadap Customer Loyalty.

\section{KAJIAN TEORI \\ Green Image}

Chen \& Chang (2012) menyatakan bahwa, green image adalah persepsi dari sebuah merek yang ada pada benak kosnumen mengenai komitmen dan kepedulian terhadap kelestarian lingkungan dari suatu produk atau jasa. Berdasarkan Dahlstrom (2011) green image merupakan sekumpulan atribut dan manfaat dari suatu merk yang dihubungkan dengan pengurangan pengaruh merk terhadap area yang dipersepsikan jadi ramah lingkungan. Keller (1993) menyatakan bahwa green image merupakan citra merk hijau yang mendapat anggapan serta terasosiasi di benak konsumen terkait dengan penawaran produk ataupun jasa.

Hal tersebut bisa dibuktikan dengan indikator green image yang diungkapkan oleh Chen (2009), diantaranya :

a. Mempunyai kredibilitas tinggi dalam menjaga komitmen dengan lingkungan.

b. Memiliki reputasi baik terhadap lingkungan.

c. Sukses dalam menjaga lingkungan.

d. Memiliki kepedulian tinggi terhadap lingkungan.

e. Merek dapat dipercaya mampu menjaga kelestarian lingkungan.

\section{Perceived CSR Capability}

Wibisono (2007) mendefinisikan bahwa CSR tanggung jawab perusahaan yang memiliki kebijakan untuk berlaku etis, meminimalkan dampak negatif dan memaksmalkan dampak positif yang mencakup aspek ekonomi dan sosial dalam rangka mencapai pembangunan yang berkelanjutan.

Kotler \& Lee (2005) menyatakan bahwa menempatkan CSR sebagai operasional bisnis yang mampu melebihi kode etik, legalitas, komersial, dan ekspektasi publik. Definisi ini menggambarkan bahwa sebuah keputusan bisnis harus mempertimbangkan kode etik dan menghargai masyarakat beserta lingkungannya.

Kotler \& Lee (2005) menyatakan bahwa penerapan CSR dapat dikategorikan menjadi 6 kategori, yaitu : Cause Promotions, Cause-Related Marketing, Corporate Social Marketing, Corporate Philantrophy, Community Volunteering dan Social Responsibility Business Practice.

\section{Customer Perception of CSR Activities: Ethical CSR}

Perilaku etis merupakan bagian dari etika yang bisa dibuktikan apabila perusahaan mengambil keputusan yang benar, sedangkan perilaku tidak etis bisa dijelaskan apabila perusahaan melakukan perbuatan yang menyimpang dari aturan (Lawrence \& Weber, 2011). Etika berkaitan dengan integritas perusahaan, bagaimana perusahaan tersebut dapat mengelola manajemen perusahaan yang baik sesuai dengan aturan serta menjalankan tugas dan kewajibannya, sehingga bisa dipercaya oleh konsumen. Lawrence \& Weber (2011) menyatakan bahwa salah satu unsur integritas adalah kejujuran dalam pelayanan kepada konsumen yang telah diatur dalam pedoman perilaku perusahaan. 
(Marin (2009) menyatakan bahwa semakin baik anggapan CSR oleh konsumen, maka semakin baik pula penilaiannya terhadap perusahaan. (Tian (2011) menyatakan bahwa persepsi $C S R$ yang positif dari konsumen berpengaruh signifikan terhadap penilaian konsumen kepada perusahaan, sehingga konsumen memiliki pengalaman baik kepada perusahaan dan tidak segan untuk menginformasikannya kepada orang lain.

\section{Customer Loyalty}

Hurriyati (2005) menyatakan bahwa loyalitas pelanggan mmiliki peran penting dalam sebuah perusahaan, mempertahankan pelanggan dapat berpengaruh pada meningkatnya kinerja keuangan dan mempertahankan kelangsungan hidup perusahaan, hal ini bisa menjadi alasan utama perusahaan untuk menarik dan mempertahankan pelanggan. Oliver (2010) menyatakan bahwa loyalitas pelanggan adalah komitmen pelanggan untuk bertahan dan berlangganan serta sikap pembelian ulang terhadap produk/ jasa terpilih secara konsisten pada masa yang akan datang. Kotler dan Keller (2012) loyalitas pelanggan adalah perilaku pelanggan yang secara konsisten menggunakan anggarannya membeli produk atau jasa dengan penjual yang sama. Kesetiaan pelanggan dapat diperoleh salah satunya dengan cara memahami keinginan dan keunikan pelanggan. Berhasilnya suatu perusahaan untuk memuaskan pelanggan dapat dilihat dari respon pelanggan yang positif mengenai suatu produk dan merekomendasikan produk kepada orang lain. Hal tersebut tentu akan membuat pelanggan setia terhadap produk perusahaan (Udayana, 2020)

\section{HASIL DAN PEMBAHASAN \\ Sifat Penelitian}

Penelitian ini merupakan penelitian kuantitatif yang dituntut menggunakan angka, mulai dari pengumpulan data, penafsiran terhadap data tersebut serta penampilan dari hasilnya

\section{Populasi dan Sampel}

Populasi yang dipakai dalam penelitian ini yaitu mahasiswa/i Universitas Sarjanawiyata Tamansiswa di Yogyakarta yang pernah menggunakan atau masih menggunakan produk The Body Shop. Sampel yang digunakan sebanyak 105 orang.

\section{Metode Pengumpulan Data}

Data dalam penelitian menggunakan data primer yang diperoleh dari pengumpulan kuesioner. Instrumen ini disusun dengan menggunakan skala likert. Setiap jawaban dari responden terhadap daftar pertanyaan yang diajukan kemudian diberi poin tertentu. Nilai tersebut bergerak antara 1 sampai 5, dengan ketentuan yaitu sangat setuju diberi poin 5, setuju diberi poin 4 , kurang setuju diberi poin 3 , tidak setuju diberi poin 2 , sangat tidak setuju diberi poin 1. 
HASIL PENELITIAN

Uji Asumsi Klasik

1. Uji Normalitas

Tabel 1. Hasil Uji Normalitas

One-Sample Kolmogorov-Smirnov Test

\begin{tabular}{|ll|r|}
\hline & & $\begin{array}{r}\text { Unstandardize } \\
\mathrm{d} \text { Residual }\end{array}$ \\
\hline $\mathrm{N}$ & Mean & 105 \\
& & .0000 \\
Normal Parameters & & 000 \\
& & 2.603 \\
& Std.Deviation & 93877 \\
& Absolute & .111 \\
Most Extreme Differences & Positive & .087 \\
& Negative & -.111 \\
Kolmogorov-Smirnov Z & & 1.135 \\
Asymp. Sig. (2-tailed) & & .152 \\
\hline
\end{tabular}

Hasil uji normalitas menunjukkan bahwa nilai sig sebesar 0,152 lebih besar dari 0,05 , dengan demikian dapat disimpulkan bahwa data penelitian berdistribusi normal.

\section{Uji Multikolinearitas}

Table 2. Hasil Uji Multikolinearitas

\begin{tabular}{|l|c|c|}
\hline \multirow{2}{*}{ (Constant) } & \multicolumn{2}{|c|}{ Collinearity Statistics } \\
\cline { 2 - 3 } $\begin{array}{l}\text { Green } \\
\text { Image }\end{array}$ & .299 & 3.345 \\
\hline $\begin{array}{l}\text { Perceived } \\
\text { Csr }\end{array}$ & & \\
Capability & .315 & 3.172 \\
\hline $\begin{array}{l}\text { Customer } \\
\text { Perception }\end{array}$ & & \\
\hline
\end{tabular}

a. Dependent Variable: Customer Loyalty

sumber data primer : diolah pada tahun 2021

Hasil uji multikolinearitas di atas menunjukkan bahwa tidak terdapat gangguan multikolinearitas karena nilai VIF kurang dari 10 dan nilai tolerance lebih besar dari 0,1. 


\section{Uji Heteroskedastisitas}

Table 3. Hasil Uji Heteroskedastisitas

\begin{tabular}{|c|c|c|c|c|c|}
\hline & \multicolumn{2}{|c|}{$\begin{array}{l}\text { Unstandardized } \\
\text { Coefficients }\end{array}$} & $\begin{array}{l}\text { Standardized } \\
\text { Coefficients }\end{array}$ & & \\
\hline & B & $\begin{array}{l}\text { Std. } \\
\text { eror }\end{array}$ & Beta & & \\
\hline (constant) & 1.632 & $\begin{array}{r}1 \\
1.124\end{array}$ & & $\begin{array}{r}1 \\
1.451\end{array}$ & $\begin{array}{r}. . \\
150\end{array}$ \\
\hline Green Image & 091 & 092 &. .177 & 980 & 329 \\
\hline $\begin{array}{l}\text { Perceived } \\
\text { Csr } \\
\text { Capability }\end{array}$ & -.075 & 127 & --.104 & $\begin{array}{r}-- \\
.588\end{array}$ & $\begin{array}{r}\ddot{ } \\
558\end{array}$ \\
\hline $\begin{array}{l}\text { Customer } \\
\text { Perception }\end{array}$ & -.020 & $\begin{array}{r}\ddot{ } \\
113\end{array}$ & --.036 & $\begin{array}{r}-- \\
.173\end{array}$ & 863 \\
\hline
\end{tabular}

a. Dependent Variable: ABS_RES

Hasil uji pada tabel di atas menunjukkan bahwa semua variabel mempunyai nilai signifikansi lebih besar dari 0,05, dengan demikian dapat disimpulkan bahwa tidak terjadi gangguan heteroskedastisitas.

\section{Analisis Regresi Linier Berganda}

Table 4. Hasil Uji Regresi Linear Berganda

\begin{tabular}{|l|c|c|c|c|c|}
\hline & \multicolumn{2}{|c|}{$\begin{array}{c}\text { Unstandardized } \\
\text { Coefficients }\end{array}$} & $\begin{array}{c}\text { Standardized } \\
\text { Coefficients }\end{array}$ & & \\
\hline & B & $\begin{array}{c}\text { Std. } \\
\text { eror }\end{array}$ & Beta & & \\
\hline (constant) & 1.314 & .973 & & 1.351 & .180 \\
\hline Green Image & .458 & .067 &. .491 & 6.880 & .000 \\
\hline $\begin{array}{l}\text { Perceived Csr } \\
\text { Capability }\end{array}$ & .591 & .094 &. .449 & 6.293 & .000 \\
\hline
\end{tabular}

a. Dependent Variable: Customer Perception

Berdasarkan hasil pengujian regresi linear berganda, dapat ditunjukkan persamaan sebegai berikut:

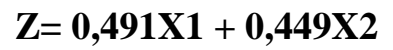

Hasil pengolahan data di atas menunjukkan bahwa koefisien regresi sebesar 0,491 (positif) dan nilai signifikansi sebesar 0,000, dengan demikian green image berpengaruh positif dan signifikan terhadap customer perception. Selanjutnya, koefisien regresi yang kedua sebesar 0,449 (positif) dan nilai signifikansi sebesar 0,000, dengan demikian 
Perceived CSR Capability berpengaruh positif dan signifikan terhadap customer perception.

\section{Analisis Regresi Linier Sederhana}

Table 5. Hasil Uji Analisis Regresi Linier Sederhana

\begin{tabular}{|c|c|r|c|r|r|}
\hline & \multicolumn{2}{|c|}{$\begin{array}{c}\text { Unstandardized } \\
\text { Coefficients }\end{array}$} & $\begin{array}{c}\text { Standardized } \\
\text { Coefficients }\end{array}$ & & \\
\hline & B & $\begin{array}{c}\text { Std. } \\
\text { eror }\end{array}$ & Beta & & \\
\hline (constant) & 1.281 & 1.560 & & .821 & .414 \\
\hline $\begin{array}{c}\text { Customer } \\
\text { Perception }\end{array}$ & 1.325 & .081 &. .849 & 16.329 & .000 \\
\hline
\end{tabular}

a.Dependent Variable: Customer Loyalty

Berdasarkan hasil pengujian regresi linear sederhana, dapat ditunjukkan persamaan sebegai berikut:

$$
\mathbf{Y}=\mathbf{0 , 8 4 9 Z}
$$

Hasil pengolahan data di atas menunjukkan bahwa koefisien regresi sebesar 0,849 (positif) dan nilai signifikansi sebesar 0,000 lebih kecil dari 0,05, dengan demikian customer perception berpengaruh positif dan signifikan terhadap customer loyalty.

\section{Uji Hipotesis}

Uji Koefisien Determinasi (R)

Tabel 6. Uji R Variabel Dependen Customer Perception Of CSR Activities: Ethical CSR

\begin{tabular}{|l|l|l|l|l|}
\multicolumn{1}{|c|}{ Model Summary } \\
\hline Model & R & $\begin{array}{l}\text { R } \\
\text { Square }\end{array}$ & $\begin{array}{l}\text { Adjusted } \\
\text { R } \\
\text { Square }\end{array}$ & $\begin{array}{l}\text { Std. } \\
\text { Error of } \\
\text { the } \\
\text { Estimate }\end{array}$ \\
\hline 1 & .879 & .773 & .768 & 1.604 \\
\hline
\end{tabular}

a. Predictors: (Constant), Perceived Csr Capability , Green Image

Hasil uji $\mathrm{R}$ di atas menunjukkan bahwa nilai $\mathrm{R}$ square sebesar 0,773 dengan demikian pada pengujian tersebut terdapat $77,3 \%$ pengaruh variabel Green Image dan Perceived CSR Capability terhadap Customer Perception Of CSR Activities: Ethical CSR serta $22,7 \%$ lainnya dipengaruhi oleh variabel lain. 
Tabel 7

Uji R Variabel Dependen Customer Loyalty

\begin{tabular}{|l|l|r|r|c|}
\hline Model & R & R Square & $\begin{array}{l}\text { Adjusted } \\
\text { R Square }\end{array}$ & $\begin{array}{l}\text { Std. Error of } \\
\text { the Estimate }\end{array}$ \\
\hline & .7 & .7 & 2.758 \\
\hline
\end{tabular}

a. Predictors: (Constant), Customer Perception

Hasil uji $\mathrm{R}$ di atas menunjukkan bahwa nilai $\mathrm{R}$ square sebesar 0,721 dengan demikian pada pengujian tersebut terdapat $72,1 \%$ pengaruh Customer Perception of CSR Activities: Ethical CSR terhadap customer loyalty serta 27,9\% lainnya dipengaruhi oleh variabel lain.

\section{PEMBAHASAN}

\section{Pengaruh Green Image Terhadap Customer Perception Of CSR Activities: Ethical CSR}

Terlihat dari pengujian hipotesis yang disajikan pada tabel 4 dapat dinyatakan bahwa green image berpengaruh positif terhadap customer perception of CSR activities: ethical CSR, pernyataan ini dapat dibuktikan dari hasil analisis linear berganda yang menunjukkan bahwa nilai sig adalah 0,000 atau lebih kecil dari 0,05 dengan demikian $\mathrm{H}_{1}$ diterima.

Dari hasil tersebut The Body Shop dapat membuktikan bahwa perusahaan mempunyai integritas tinggi dalam menjaga komitmen baiknya terhadap lingkungan, memiliki reputasi yang baik terhadap lingkungan, memiliki kesuksesan dalam menjaga lingkungan dan memiliki kepedulian tinggi terhadap lingkungan. Citra positif yang didapatkan oleh perusahaan dapat memberikan dampak yang baik seperti pengakuan bahwa perusahaan dapat dipercaya.

Hasil penelitian ini mendukung penelitian sebelumnya yang dilakukan oleh Santoso (2017) tentang Pengaruh Green Marketing dan Corporate Social Responsibility terhadap Brand Image pada produk Tupperware.

\section{Pengaruh Perceived CSR Capability Terhadap Customer Perception Of CSR Activities: Ethical CSR}

Hasil pengujian hipotesis yang disajikan pada tabel 4 dapat dinyatakan bahwa perceived CSR capability berpengaruh positif terhadap customer perception of CSR activities: ethical CSR, pernyataan ini dapat dibuktikan dari hasil analisis linear berganda yang menunjukkan bahwa nilai sig adalah 0,000 atau lebih kecil dari 0,05 dengan demikian $\mathrm{H}_{2}$ diterima.

Kedua variabel saling berpengaruh positif karena perusahaan The Body Shop mampu memahami kebutuhan pelanggan dan melayani permintaan pelanggan melalui informasi yang sudah di dapat. Hal tersebut bisa terjadi karena perusahaan menekankan pentingnya tanggung jawab sosial kepada karyawan dan karyawan diharuskan untuk memberikan informasi lengkap dan akurat kepada semua pelanggan. komunikasi yang terjalin baik antara karyawan dan pelanggan dapat memberikan pengaruh yang baik ke perusahaan. Perusahaan tentu akan mengetahui apa saja keinginan pelanggan dan pelanggan juga akan mengetahui informasi yang mereka perlukan. 
Hasil penelitian ini mendukung penelitian terdahulu yang dilakukan oleh Muhadjir \& Gita (2011) tentang Pengaruh Penerapan CSR Terhadap Persepsi Nasabah Bank dan Dampaknya Terhadap Corporate Image.

\section{Pengaruh Customer Perception Of CSR Activities: Ethical CSR Terhadap Customer Loyalty}

Hasil pengujian hipotesis yang disajikan pada tabel 5 dapat dinyatakan bahwa Customer perception Of CSR Activities: Ethical CSR berpengaruh positif terhadap Customer Loyalty, pernyataan ini dapat dibuktikan dari hasil analisis linear berganda yang menunjukkan bahwa nilai sig adalah 0,000 atau lebih kecil dari 0,05 dengan demikian $\mathrm{H}_{3}$ diterima.

Perusahaan telah menekankan pentingnya tanggung jawab sosial sosial dan memberikan program pelatihan etika untuk karyawannya serta karyawan diharuskan untuk memberikan informasi yang lengkap dan akurat kepada pelanggan. Apabila pelanggan diperlakukan dengan baik dan ramah serta karwayan dapat memberikan informasi yang diperlukan oleh pelanggan maka pelanggan akan merasa nyaman dan memiliki pengalaman berbelanja yang baik di outlet The Body Shop, hal tersebut dapat berpengaruh pada perusahaan karena dari pelayanan yang baik pelanggan akan melakukan pembelian ulang bahkan mereferensikan kepada pelanggan lain tentang produk atau perusahaan.

Hasil penelitian ini mendukung penelitian sebelumnya yang dilakukan oleh Felicia dan Gesti (2018) tentang Pengaruh CSR Terhadap Customer Loyalty Melalui Price Fairness Sebagai Variable Mediasi Pada Mahkota Jaya Tuban.

\section{SIMPULAN}

Berdasarkan Hasil Penelitian dan Pembahasan, maka dapat ditarik kesimpulan bahwa :

1. Terdapat pengaruh positif green image terhadap customer perception of CSR activities: ethical CSR. Hal ini dibuktikan dari hasil analisis linear berganda yang menunjukkan bahwa nilai sig adalah 0,000 atau lebih kecil dari 0,05 dan koefisien regresi sebesar 0,491 .

2. Terdapat pengaruh positif perceived CSR capability terhadap customer perception of CSR activities: ethical CSR. Hal ini dapat dibuktikan dari hasil analisis linear berganda yang menunjukkan bahwa nilai sig adalah 0,000 atau lebih kecil dari 0,05 dan koefisien regresi sebesar 0,449.

3. Terdapat pengaruh positif Customer perception Of CSR Activities: Ethical CSR terhadap Customer Loyalty. Hal ini dapat dibuktikan dari hasil analisis linear berganda yang menunjukkan bahwa nilai sig adalah 0,000 atau lebih kecil dari 0,05 dan koefisien regresi sebesar 0,849 .

\section{DAFTAR PUSTAKA}

Achda, B. T. (2006). The sociological context of corporate social responsibility development and implementation in Indonesia,. Corporate Social Responsibility and Environmental Management, 13, 300-305.

Ardianti, F. \& R. (2008). Analisis perilaku konsumen bogor terhadap produk kosmetik hijau. Jurnal Manajemen \& Agribisnis, 5 (1), 16-22.

Chen. (2009). The Drivers of Green Brand Equity: Green Brand Image, Green Satisfaction, and Green Trust. Journal of Business Ethics, 93 nomor 2, 307-319.

Chen \& Chang. (2012). Enhance green purchase intentions: The roles of green perceived value, green perceived risk, and green trust. Management Decision, 50(3), 502520 . 
Dahlstrom, R. (2011). Green Marketing Management. Journal of Consumer Marketing.

Dewi, S. (2011). Etika Bisnis: Konsep Dasar Implementasi \& Kasus. Denpasar: Udayana University Press.

Felicia dan Gesti. (2018). Pengaruh Corporate Social Responsibility Terhadap Customer Loyalty Melalui Price Fairness Sebagai Variabel Mediasi Pada Mahkota Jaya Tuban. AGORA, 6(2).

Harris, P. G. (2006). Environmental perspectives and behavior in China: Synopsis and Bibliography. Environment and Behavior, 38(1), 5-21.

Herri, P. \& K. (2006). Analisis Persepsi Masyarakat Terhadap Produk Hijau: Tinjauan Faktor Demografi, Psikologis, Sosial dan Budaya (kasus kota padang). Jurnal Bisnis \& Manajemen.

Hurriyati, R. (2005). Bauran Pemasaran dan Loyalitas Konsumen. Alfabeta.

Ida Bagus Nyoman Udayana, T. dan I. A. (2020). Membangun orientasi pelanggan untuk meningkatkan salesperson consulting performance. Jurnal Manajemen Maranatha, 19(2), 93-104.

Kaufmann, P. \& O. (2012). Factors Affecting Consumers' Green Purchasing Behavior: An Integrated Conceptual Framework. Amfiteatru Economic, XIV (31).

Keller, K. L. (1993). Conceptualing, Measuring, and Managing Customer Based Brand Equity. Journal of Marketing, 57 nomor 1.

Kotler, P., \& Lee, N. (2005). Corporate Social Responsibility, Doing The Most Good for Your Company and Your Cause. Journal of Business Ethics.

Kotler dan Keller. (2012). Marketing Management Global Edition (14th ed.). Pearson. Prentice Hall.

Lawrence \& Weber. (2011). Business and society: Stakeholders, Ethics, Public Policy. Journal of Business Ethics.

Marin, L., Ruiz, S., \& Rubio, A. (2009). The Role of Identity Salience in the Effects of Corporate Social Responsibility on Consumer Behaviour. Journal of Business Ethics, 84, 65-78.

Muhadjir \& Gita. (2011). Pengaruh Penerapan Corporate Social Responsibility Terhadap Persepsi Nasabah Bank dan Dampaknya Terhadap Corporate Image. Journal The WINNERS, 12 (2), 180-195.

Oliver, R. (2010). Satisfaction: A Behavioral Perspective on the Consumer(McGraw-Hill series in marketing). McGraw-Hill Education.

Tian, Zhilong., R. W. and W. Y. (2011). Consumer Responses to Corporate Social Responsibility (CSR) in China. Journal of Business Ethics, 101, 197-212.

Voni Prila Santoso. (2017). Pengaruh Green Marketing dan Corporate Social Responsibility Terhadap Brand Image Pada Produk Tupperware. E-Jurnal Manajemen Unud, 6(3), 1592-1616.

Wibisono, Y. (2007). Membedah Konsep \& Aplikasi CSR. Gresik: Fascho Publishing. 